\title{
What Drives Excess Trading during the COVID-19 Pandemic?
}

\author{
Phaik Nie Chin*
}

\begin{abstract}
Manuscript type: Research paper

Research aims: This study aims to examine the underlying psychological and sociological factors that drive excess trading in the Malaysian stock market during a global health crisis such as the COVID-19 pandemic.

Design/Methodology/Approach: A self-administered online questionnaire was collected from 271 individual investors to examine the association between big-five personality traits and trading frequency. Demographic information and investment behaviours of investors were also included in the study. The multinomial logit regression model was used to test the research hypotheses.

Research findings: Findings show that personality traits such as openness to experience and agreeableness have a significant influence on trading frequency. Demographic factors and investment behaviours such as gender, household income level, years of investment experience and type of investor all have a significant positive relationship with trading frequency.

Theoretical contribution/Originality: This study contributes to the current investor behaviour literature in Malaysia, which remains to be very limited, especially during a global health crisis. The study indicates that personality traits, demographic, socio-economic factors, and investment behaviours affect the trading frequency of Malaysian investors.
\end{abstract}

* Phaik Nie Chin is a Senior Lecturer at the Graduate School of Management, Univeristi Sains Malaysia, Malaysia. Email: phaikniechin@usm.my

Acknowledgment: I would like to acknowledge Universiti Sains Malaysia for funding through the Bridging-Incentive Universiti Sains Malaysia (grant number: 304/PPAMC/6316424) that support this research.

https://doi.org/10.22452/ajba.vol14no1.5 
Practitioner/Policy implication: This study offers insights for financial institutions and individual investors on the type of personality traits, demographic, socio-economic factors, and investment behaviours that drive excess trading during a global health crisis. The findings provide important contributions to avoid serious mistakes in investment analysis and trading profitable investment strategies, thus improving individual and team performance.

Research limitation/Implications: Some results are not significant and may be limited due to the small sample size used in this study. Future research could recruit more retail investors to confirm the significance level of those variables. Besides, the study can be conducted after the COVID-19 pandemic to explore whether there is any significant difference in the variables during and after the global health crisis.

Keywords: COVID-19, Big Five Personality Traits, Trading Frequency, Demographics, Investment Experience

JEL Classification: G4, G41, G410

\section{Introduction}

The global health crisis such as the COVID-19 pandemic has posed numerous challenges to the global financial market since its first outbreak in Wuhan, China. With the outbreak of the COVID-19 pandemic in January 2020, the world has been watching the stock market performance that could be badly hit by the slowing down of economic activities. On the 18th of March 2020, Malaysia's FBM KLCI has dropped to 1239.01 after the announcement of the movement control order (MCO) (FBM KLCI, 2020). When Malaysians were expecting a decrease in stock market performance, Malaysia's FBM KLCI has surged from 1239.01 to 1606.42 on the 21st of July 2020. Investors have shoved a total of RM57.66 billion into seven glove counters listed on Bursa Malaysia since March 1 when the pandemic theme started in the local market. From March 1 to July 6, the turnover of RM57.66 billion among seven stocks represented $19.04 \%$ of the FBM KLCI's total turnover of RM300.4 billion (Aziz \& Yi, 2020). This was not only observed in Malaysia, Anh and Gan (2020) studied the impact of COVID-19 on stock performance during the pre- and post-lockdown period in Vietnam and discovered a positive influence on the stock market performance. This is further supported by Topcu and Gulal (2020), who investigated the impact of COVID-19 on 26 emerging stock markets including Malaysia, Indonesia and Thailand from March 10, 2020, to April 30, 2020. Their study revealed that the 
negative impact of the COVID-19 pandemic has gradually declined and begun to taper off by mid-April.

Based on the weak-form efficient market hypothesis under behavioural finance theory, market information is homogeneous, and thus abnormal profit may not be possible eventually. However, recent events during the lockdown period in Malaysia have demonstrated that anyone who enters the bursa market in Malaysia can earn a substantial profit. This has triggered more participation and trading frequency from retail investors. Perhaps, such movement can only be explained by psychological factors and human behaviour, as Wagner (2020) mentioned that the COVID-19 event is an opportunity for the world to explore more about investor psychology and human behaviour. The literature on behavioural finance has been trying to understand such irrational movement by investors since Black Monday 1987 (Shiller et al., 1991). Shiller et al. (1991) concluded that most investors interpreted the market crash because of other investors' psychology. However, what about the influence of investor psychology during a global health disaster?

Since the past decades, a voluminous literature has been exploring the effect of psychological factors such as overconfidence bias (Gervais \& Odean, 2001; Glaser \& Weber, 2007; Kourtidis et al., 2017; Odean, 1998), confirmation bias (Duong et al., 2014; Park et al., 2013), self-serving bias (Chin et al., 2018; Moosa \& Ramiah, 2017), and behavioural biases such as disposition effect, mental accounting, heuristics bias, herding, etc. on investors' anomaly such as excessive trading volume or trading frequency (Baker et al., 2019; Barber et al., 2009; Barberis \& Huang, 2001; Chen et al., 2007; Choe \& Eom, 2009). Overconfidence affects the financial market, and studies have found that overconfidence increases expected trading volume and price volatility (Gervais \& Odean, 2001; Glaser \& Weber, 2007; Odean, 1998), and men traded more than women because men are more overconfident than women (Barber \& Odean, 2001a). Statman et al. (2006) investigated the trading volume implications of the overconfidence hypothesis on NYSE/AMEX shares and found that investors with biased self-attribution increased their trading volume after past returns. Graham et al. (2009) used data from UBS/Gallop investor survey and discovered that overconfident investors tend to trade more frequently than those who are not. The same findings were found by Kourtidis et al. (2017) who collected 373 survey questionnaires from individual investors in Greece.

In a field experiment, Park et al. (2013) investigated confirmation bias among 502 investors in Korea using stock message boards. They 
found that biased investors choose messages that support their beliefs, exhibiting confirmation bias, and trade more actively. This is also supported by Duong et al. (2014), who found confirmation bias among UK investors. Their study concluded that pessimistic value investors tend to overreact to bad information, whereas optimistic value investors overreact to good information. In a one-shot experiment, Chin et al. (2018) explored the association between self-serving bias and trading volume among 193 investors and discovered that biased investors tend to have higher trading volume. Overconfidence is said to be positively related to self-serving bias (Moosa \& Ramiah, 2017). Beracha et al. (2014) studied the impact of cultures on institutional investors' trading frequency. Their findings suggested a negative relationship between the two. So far, most finance studies in the past have explained investors' trading anomaly by exploring overconfidence bias, confirmation bias, self-attribution, or behavioural biases such as herding, disposition effect, mental accounting, heuristic bias, and representative bias. Even though personality traits have also been known as an important factor that will affect human decision-making (McCrae \& Costa, 1997), there are still limited studies found in the finance literature (Fung \& Durand, 2014), especially during a global health disaster.

To the best of my knowledge, Wang et al. (2014) and Tauni et al. (2015) are two early papers that relate personality traits and investment behaviours. Wang et al. (2014) used a laboratory experiment in China to investigate personality traits as a moderator between investor's emotion and investment return; whereas Tauni et al. (2015) used a survey questionnaire on 333 individual investors to investigate personality traits as a moderator between information acquisition and trading frequency in the Chinese futures market. Wang et al. (2014) revealed that positive (negative) emotion has a positive (negative) relationship with investment return and the moderating effect of extraversion (neuroticism) is significant. Tauni et al. (2015) showed that extraversion and conscientiousness positively moderate the relationship between information acquisition and trading frequency. A recent study by Baker et al. (2019) used a survey questionnaire to explore the relationship between personality traits and behavioural biases; they summarised that neuroticism, extraversion and conscientiousness are associated with the behavioural biases of individual investors. However, previous studies were conducted in the absence of a global health crisis.

Few studies have investigated investor psychology during the COVID-19 pandemic. For example, Fernandez-Perez et al. (2021) looked 
at the impact of national culture (i.e., individualism and uncertainty avoidance) on stock market responses to the COVID-19 pandemic. Their study covered 63 countries including Malaysia. Their findings concluded that countries with lower individualism and higher uncertainty avoidance during the first three weeks after a country's first COVID-19 case announcement have larger declines and greater volatility in their stock markets. Smales (2021) used Google search volume (GSV) as a proxy for investor attention and found that rising investor attention is associated with larger volatility in the financial market of the G20 nations. Kizys et al. (2021) adopted cross-sectional absolute deviation (CSAD) and the cross-sectional standard deviation (CSSD) as measures of investor herding behaviour showing significant herding behaviour among international investors during the COVID-19 pandemic. Herding behaviour during the COVID-19 pandemic is also being found in other studies in the context of the energy stock market (Chang et al., 2020) and medical stocks (Sun et al., 2021).

Based on the existing literature, this study contributes in two ways. First, to contribute to existing personality traits literature in the financial market, which is still limited, especially in emerging countries such as Malaysia (Akhtar et al., 2018). The study found that investors with higher traits in openness to experience and agreeableness trade significantly different than those with lower traits. Second, to contribute findings in the context of a global health crisis. Even though personality traits showed a stable coefficient (Costa \& McCrae, 2004), personality traits may change based on a situation or a major event in life (Specht et al., 2011). The findings may help to provide useful information on the type of personality traits that may have overreacted during the COVID-19 pandemic.

The paper is organised as follows. Section 2 highlights the theoretical framework, literature review and hypothesis development, while Section 3 explains the methodology. Section 4 reviews the results and discussions, and Section 5 concludes with the implications of the study.

\section{Theoretical Framework, Literature Review and Hypothesis Development}

\subsection{Efficient Market Hypothesis (EMH) and Adaptive Markets Hypothesis (AMH)}

Based on the classical EMH, the price fully incorporates all available information and rational expectations of all market participants. The more efficient the market, the more random and unpredictable the 
price changes. This pattern is driven by profit opportunities by many active market participants. When market participants incorporate their information into market prices, profit opportunities are quickly eliminated. Thus, they cannot profit (Fama, 1970, 1995). The neoclassical EMH further summarised the EMH by the "three Ps of Total Risk Management": prices, probabilities and preferences, which later became fundamental for all forms of decision-making under uncertainty (Lo, 1999). The EMH assumes that all investors have rational expectations, prices fully reflect all available information and marginal-utility weighted prices follow martingales. According to the EMH, market forces will always act to return prices to rational levels.

However, since the crash of Black Monday 1987, economists and psychologists started to explore the departure of general equilibrium in the forms of specific behavioural biases, which could not be explained by the EMH. Many similar market crashes and panics have shown that market forces of irrationality are stronger than the forces of rationality during the pandemic. Behaviourists argue that these market forces of irrationality by investors can be influenced by investors' cognitive or psychological factors such as heuristic bias, representative bias, personality traits, etc. (Kahneman \& Tversky, 1984, 2013; Shiller et al., 1991). Thus, this study aims to explain the market forces of irrationality during the COVID-19 pandemic with psychological factors such as personality traits, which is still limited in the study of behavioural finance (Fung \& Durand, 2014).

The application of personality traits to investment decisions is further supported by a new version of EMH - adaptive markets hypothesis $(\mathrm{AMH})$ - that aims to incorporate both EMH and behavioural finance (Lo, 2004, 2005). The primary components of the AMH consist of the following ideas: (1) individuals act in their self-interest, (2) individuals make mistakes, (3) individuals learn and adapt, (4) competition drives adaptation and innovation, (5) natural selection shapes market ecology, and (6) evolution determines market dynamics. These ideas are contradicted with traditional EMH where individuals do not make mistakes, learn, and adapt because of the static market environment and market prices are always in equilibrium. Based on the $\mathrm{AMH}$, prices reflect as much information as dictated by the combination of current environment conditions (i.e., COVID-19 pandemic) and the number and nature of investors in the market. The nature of investors refers to distinct groups of market participants such as pension funds, retail investors, market makers and hedge-fund managers, who all behave 
in a common manner and competing for resources in a given market. In one of the applications of $\mathrm{AMH}$, psychological surveys such as personality traits assessment (Costa \& McCrae, 2010) have always been adopted to measure individuals' personality and relate these measures to risk attitudes and investment decisions (Lo, 2005). Understanding personality traits can help to provide a behavioural explanation for a financial phenomenon (Fung \& Durand, 2014).

\subsection{The Big-Five Personality Traits}

Personality is a key determinant of human behaviour. In a given situation, personality forms a specific inclination towards a certain characteristic reaction; therefore, personality can be regarded as a key driver of human behaviour (Heinström, 2003). This study adopted the theory of the five-factor model of personality traits (also known as the Big Five), which is the most commonly used in personality research (McCrae, 2012). The Big-Five personality traits summarise personality using five higher-order personality factors such as extraversion, agreeableness, conscientiousness, neuroticism, and openness to experience to account for the co-variation of most personality traits. Table 1 illustrates the definition of the five personality factors.

Table 1: The Big-Five Personality Traits

\begin{tabular}{|c|c|c|}
\hline Personality traits & High traits & Low traits \\
\hline Extraversion & $\begin{array}{l}\text { sociable, active, optimistic, } \\
\text { fun-loving, talkative }\end{array}$ & reserved, aloof, quiet \\
\hline Agreeableness & $\begin{array}{l}\text { trusting, altruistic, good- } \\
\text { natured, empathic, helpful }\end{array}$ & $\begin{array}{l}\text { cynical, rude, suspicious, } \\
\text { uncooperative, irritable, } \\
\text { manipulative, vengeful, } \\
\text { ruthless }\end{array}$ \\
\hline Conscientiousness & diligent, self-control & $\begin{array}{l}\text { lazy, aimless, hedonistic, } \\
\text { lax, careless }\end{array}$ \\
\hline Neuroticism & $\begin{array}{l}\text { anger, hostility, depression, } \\
\text { anxiety }\end{array}$ & calm, emotionally stable \\
\hline $\begin{array}{l}\text { Openness to } \\
\text { Experience }\end{array}$ & $\begin{array}{l}\text { imaginative, curious, open } \\
\text { to unconventional ideas } \\
\text { and values }\end{array}$ & $\begin{array}{l}\text { conventional, dogmatic in } \\
\text { beliefs and attitudes, } \\
\text { emotionally unresponsive }\end{array}$ \\
\hline
\end{tabular}

Source: Adopted from Fung and Durand (2014). 
Personality traits have been shown in the past to have a significant impact on an individual's decision making ( $\mathrm{Xu}$ et al., 2016), financial decisions (Slovic, 1972), investor behaviour and performance in the stock market (Borghans et al., 2008; Camgoz et al., 2011; Sadi et al., 2011), stock market participation (Conlin et al., 2015), debt acquisition and the holding of financial assets (Brown \& Taylor, 2014), overconfidence and overreaction in the market (Durand et al., 2013), short term and long term investment intentions (Mayfield et al., 2008). The following are the hypothesis development for each predictor.

\subsubsection{Neuroticism (N)}

Neuroticism refers to emotional stability, depression, and self-centeredness. High $\mathrm{N}$ individuals tend to have irrational ideas, be less able to control their impulses, poor in resisting temptations and coping with stress. They are more prone to experience negative emotions such as fear and anger. In contrast, low $\mathrm{N}$ individuals are emotionally stable, relaxed and able to face stressful situations without becoming upset (Costa \& McCrae, 2010). Durand et al. (2013) found that high N investors trade less in an experiment. However, many found otherwise. When price changes in the financial market, high $\mathrm{N}$ investors may experience extreme emotions, exhibit irrational behaviour and trade too much especially when they acquire information from financial advice (Durand et al., 2008; Tauni et al., 2015; Tauni et al., 2017; Zhang et al., 2014). The AMH framework mentions that individuals' investment decisions are also affected by current environmental conditions. Therefore, this study hypothesised that high $\mathrm{N}$ investors may trade more during the COVID-19 pandemic because they are more inclined to experience extreme emotions and exhibit irrational behaviour.

$\mathrm{H}_{1}$ : High $\mathrm{N}$ investors trade more than low $\mathrm{N}$ investors.

\subsubsection{Extraversion (E)}

Warmth and positive emotions are the two facets that are responsible for this association (Costa \& McCrae, 1984). High E individuals are sociable, assertive, active, upbeat, energetic, and optimistic but lack deep analysis and may be overly focused on external events. They like excitement and stimulation and tend to be cheerful in disposition. Low E individuals are reserved, independent, even-paced, shy and prefer to be alone, but 
not necessarily suffer from social anxiety, unhappy or pessimistic (Costa $\&$ McCrae, 2010). Tauni et al. (2017) showed that extroverts trade more when they acquire information through word-of-mouth, whereas most studies have found that high $\mathrm{E}$ individuals can acquire more information for investment decisions due to their good relationship with others in the market, and thus, they are less likely to overreact to news, more likely to make reasonable investment decisions and trade less (Durand et al., 2008, 2013; Zhang et al., 2014), especially when they use financial advice (Tauni et al., 2017). Thus, this study hypothesised that high E investors are more sociable, emotionally stable, and always seek advice on decision-making, making them more rational and trade less in a global health crisis.

$\mathrm{H}_{2}$ : High E investors trade less than low E investors.

\subsubsection{Openness to Experience $(O)$}

High $\mathrm{O}$ individuals are more willing to entertain novel ideas and unconventional values, more creative, experience both positive and negative emotions more keenly than low $\mathrm{O}$ individuals. They are positively correlated with intelligence and achievement (Douglas et al., 2016). Low $\mathrm{O}$ individuals tend to be conventional in their behaviour and conservative in their outlook, with a narrower scope and lower intensity of interests. They prefer the familiar to the novel, and their emotional responses are somewhat muted (Costa \& McCrae, 2010). Studies believe that high $\mathrm{O}$ individuals are thoughtful information seekers (Heinstrom, 2010), knowledgeable and intellectual, and thus, able to think critically in problem analysis and do not engage in overtrading (Borgatta, 1964; Zhang et al., 2014). However, Kleine et al. (2016) examined the crosssectional determinants of individual trading activity based on given big-five personality traits and found that openness is the main driver of excess trading and endanger wealth. Grinblatt and Keloharju (2009) mentioned that investors who seek sensation tend to trade more. High $\mathrm{O}$ investors easily accept new market information and may frequently change investment portfolios with changes in market situations (Pak \& Mahmood, 2015), especially when they use financial advice (Tauni et al., 2017). These studies concluded that high $O$ individuals positively relate to excess trading. Therefore, this study hypothesised that high $\mathrm{O}$ investors would trade more during the COVID-19 pandemic due to changes in the market situation and more new information are released daily.

$\mathrm{H}_{3}$ : High $\mathrm{O}$ investors trade more than low $\mathrm{O}$ investors. 


\subsubsection{Agreeableness (A)}

The agreeable person is fundamentally altruistic and popular. They are sympathetic to others and eager to help them, believing that others will be equally helpful in return. By contrast, low scorers on A, disagreeable or antagonistic people, are egocentric, sceptical of others' intentions, and competitive rather than cooperative (Costa \& McCrae, 2010). High A individuals are more likely to rely on analyst's opinion and find it difficult to make their own investment decision and resulting in herd behaviour (Cingl, 2013; Pak \& Mahmood, 2015; Zhang et al., 2014). Numerous studies have found high A investors tend to trade more than low A investors (Durand et al., 2013; Tauni et al., 2015, 2017; Zhang et al., 2014). Recent studies have highlighted significant herding behaviours during the COVID-19 pandemic (Chang et al., 2020; Kizys et al., 2021; Sun et al., 2021). Thus, hypothesis 4 was developed as follows because high A individuals are more likely to herd.

$\mathrm{H}_{4}$ : High A investors trade more than low A investors.

\subsubsection{Conscientiousness (C)}

This domain is also known as the will to achieve (Digman \& TakemotoChogk, 1981). The conscientious individual is purposeful, strong-willed, self-controlled, organised, scrupulous, punctual, reliable, compulsive neatness and workaholic, whereas the low scorer is more lackadaisical in working toward their goals and hedonistic (Costa \& McCrae, 2010; McCrae et al., 1986). Some studies have observed a positive relationship between conscientiousness and trading frequency (Durand et al., 2013; Tauni et al., 2015) whereas others have not. For example, Pak and Mahmood (2015) and Zhang et al.( 2014) believed that high C individuals tend to have a certain degree of confidence and are careful, analytical, methodological, self-disciplined, having clear investment goals, and thus will not trade excessively because such individuals do not make decisions without adequate experience and information. Besides, they control their desires to buy stocks with rising prices and sell stocks with falling prices, resulting in high financial performance (Camgoz et al., 2011). $H_{5}$ has been developed as follows to test its relationship in the context of a global health crisis.

$\mathrm{H}_{5}$ : High $\mathrm{C}$ investors trade less than low $\mathrm{C}$ investors. 


\subsection{Demographic, socio-economic variables and Investment Behaviours}

A voluminous literature has shown that investors' demographic and socioeconomic status affect their investment behaviours and decision (Fung \& Durand, 2014; Zhang \& Zheng, 2015). Graham et al. (2009) used data from the USB/Gallop investor survey and found that men exhibit a larger competent effect, and thus trade more than women. Barber \& Odean (2001a) used account data for over 35,000 households to analyse the common stock investments of men and women from February 1991 through January 1997; their study found that men are more confident, and thus trade 45 per cent more than women. Besides, Tauni et al. (2017) investigated the relationship between personality traits and trading behaviours of Chinese investors also observed that men trade more than women in the Chinese stock market.

Chawla (2014) collected 413 usable data from mutual fund investors using a survey questionnaire to explore the effect of age, sex, educational qualification, marital status, profession, and income on their investment decisions in terms of the credibility of mutual funds. Their results showed significant differences between gender and profession. Men are more concerned about the credibility of mutual funds than women, who make better investment decisions, and businessmen are more concerned about the credibility of mutual funds than other professions. However, their study did not show a significant difference in the income level. Mak and Ip (2017) examined the psychological attributes, demographic attributes and sociological attributes that may affect mainland China and Hong Kong investors in making decisions on the number of fund shares held and the choice of country-specific financial investment options. The study found that age, gender, income level, education level, investment experience and marital status significantly affect the amount of fund shares held by investors, whereas all the variables except gender significantly affect the choice of country-specific financial investment options. Kaustia and Knüpfer (2008) and Seru et al. (2010) also confirmed that experience is positively related to investor behaviours. Investors who have experienced positive returns in IPO tend to subscribe again (Kaustia \& Knüpfer, 2008) and investors learned from their trading experiences, some would stop trading after realising that their ability is poor and some would trade better after having more experiences (Seru et al., 2010). Based on the past findings, the following hypotheses were developed to test the relationship between age, gender, yearly 
household income, years of investment experience, type of investor and trading frequency.

$\mathrm{H}_{6 \mathrm{a}}$ : Age is positively associated with trading frequency.

$\mathrm{H}_{6 \mathrm{~b}}$ : Men trade more than women.

$\mathrm{H}_{6 \mathrm{c}}$ : Household income level is positively associated with trading frequency.

$\mathrm{H}_{6 \mathrm{~d}}$ : Years of investment experience is positively associated with trading frequency.

$\mathrm{H}_{6 \mathrm{e}}$ : Full-time investors trade more than part-time investors.

Based on the above, Figure 1 illustrates the research framework of this study.

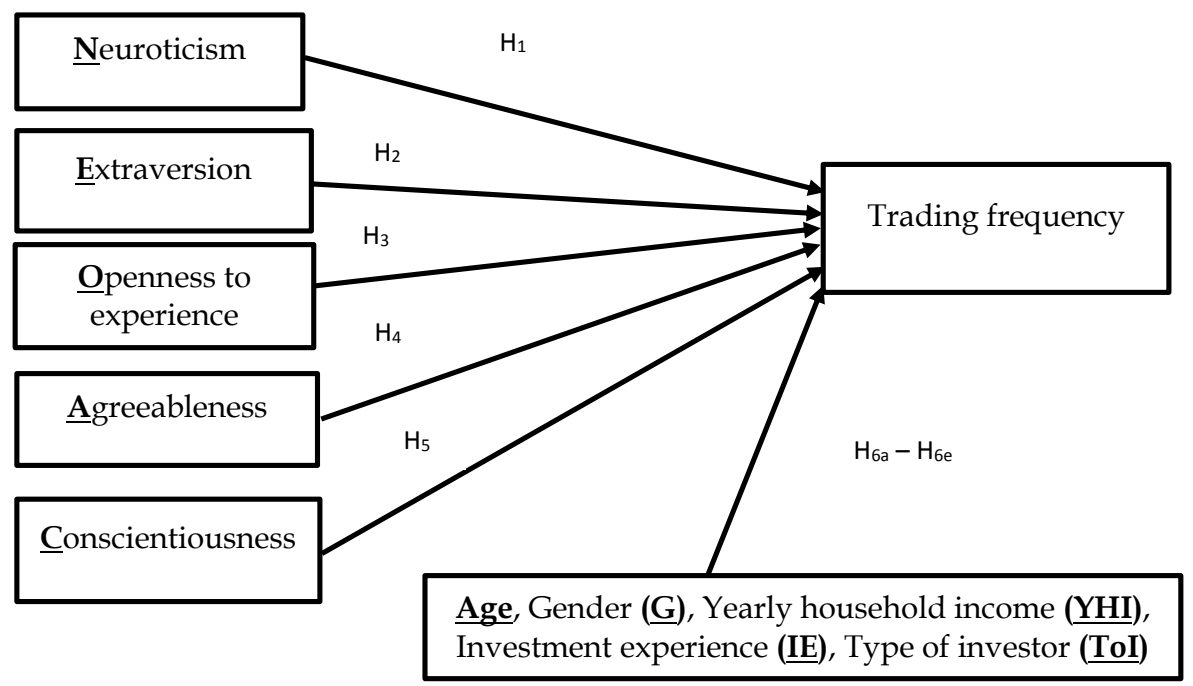

Figure 1: Research Framework

\section{Methodology}

\subsection{Data Collection and Sample}

The data for this study was collected from primary sources through convenient sampling from the pool of retail investors residing in Malaysia. A self-administered online questionnaire was sent to individual investors through brokers and financial advisors who work in banks, investment firms and trading firms, as well as shared through social 
media such as WhatsApp and Facebook to recruit more retail investors. As the questionnaire was self-administered, a validity check, such as whether the respondents are currently active in the stock market and whether they have answered the questions accurately and honestly at the end of the personality questionnaire, was included to ensure the validity and usefulness of the data. This study conducted power analysis using $G^{*}$ Power (Faul et al., 2007) to compute the sample size. Taking the odds ratio of $2,5 \%$ significant level and statistical power of 0.8 , a minimum sample size of 148 was needed for this study.

\subsection{Measurements of Variables}

The questionnaire was designed into two sections. The first section consisted of personality traits questionnaires adopted from NEO FiveFactor Inventory-3 (Form S, NEO-FFI-3) (Costa \& McCrae, 2010), which has been frequently cited in the literature of management and psychology (Tauni et al., 2018). There was a total of 60 questions, which measured the five personality traits of this study (Neuroticism, Extraversion, Openness, Agreeableness and Conscientiousness). Each personality trait had its own 12 questions to ensure that the questions used in the study cover most of the relevant thoughts, feelings and actions (Costa \& McCrae, 2010). All respondents answered the questions in a 5-point Likert scale ranging from Strongly Disagree (1), Disagree (2), Neutral (3), Agree (4) to Strongly Agree (5). A total of 25 items of personality measure was reversed score to inhibit biased responses.

In the second section, respondents filled out their demographic information such as gender, age, marital status, education, nationality, yearly household income and occupation. Then, respondents answered questions related to their investment behaviours such as full time or part-time investor, year of investment experience, and frequency of investment. The questionnaire on investment behaviours was adapted and adopted from Akhtar et al. (2018) and Tauni et al. (2015).

The predictor variables included in this study are neuroticism extraversion, openness to experience, agreeableness, conscientiousness, age, gender, yearly household income, type of investor (full time/parttime), and years of investment experience. The dependent variable tested in this study was the frequency of investment, which was measured by asking investors "What is your frequency of investment in the past year?", adopted and adapted from past studies (Baker et al., 2019; Tauni et al., 2017). The Stata coding for each variable is illustrated in Table 4. 


\subsection{Statistical and Econometric Model}

All the analysis was conducted using Stata (version 16). The score of the big five personality traits was calculated based on the combined T-score as per the instruction under Costa and McCrae's (2010) professional manual. The T-score is ranging from very low $(\mathrm{T}$-score $=<34$ ), low (T-score 35-44), average (T-score 45-55), high (T-score 56-65) and very high $(\mathrm{T}$-score $=>66)$. Subjects with higher T-score have a higher probability to exhibit higher traits than those with lower T-score. Table 2 shows the mean and standard deviation based on the T-score for this study.

Table 2: Means and Standard Deviations based on T-score

\begin{tabular}{|c|c|c|c|c|c|c|}
\hline \multirow[t]{2}{*}{ Variables } & \multicolumn{2}{|c|}{ Male } & \multicolumn{2}{|c|}{ Female } & \multicolumn{2}{|c|}{ Combined } \\
\hline & $\mathrm{M}$ & SD & M & SD & $\mathrm{M}$ & SD \\
\hline $\mathrm{N}=$ Neuroticism & 53.02 & 8.651 & 49.99 & 9.008 & 51.32 & 8.746 \\
\hline $\mathrm{E}=$ Extraversion & 52.91 & 9.121 & 47.19 & 8.746 & 49.63 & 8.911 \\
\hline $\mathrm{O}=$ Openness to Experience & 51.27 & 7.177 & 47.92 & 6.850 & 49.48 & 6.898 \\
\hline $\mathrm{A}=$ Agreeableness & 47.73 & 9.394 & 43.79 & 9.190 & 45.85 & 8.874 \\
\hline$C=$ Conscientiousness & 51.08 & 9.011 & 48.90 & 8.665 & 49.87 & 8.807 \\
\hline
\end{tabular}

Note: $\mathrm{M}=$ Mean; $\mathrm{SD}=$ Standard Deviation, Male $\mathrm{N}=96 ;$ Female $\mathrm{N}=135$.

This study adopted the multinomial logistic regression model because the dependent variable (i.e., frequency of investment) is a nominal variable categorised as low, medium, and high frequency. The multinomial logistic regression model estimates the odds of being in a category versus the base category of a nominal variable and it can be expressed as in Equation (1).

$$
\ln \left[\frac{\pi\left(Y=J \mid x_{1}, x_{2}, \ldots \ldots, x_{p}\right)}{\pi\left(Y=J \mid x_{1}, x_{2}, \ldots \ldots . ., x_{p}\right)}\right]=\alpha_{j}+\beta_{j 1} X_{1}+\beta_{j 2} X_{2}+\cdots+\beta_{j p} X_{p}
$$

where $j=1,2, \ldots ., J-1$; $J$ is the base category, which can be any category but is generally the highest one; $\alpha_{j}$ are the intercepts; and $\beta_{j 1}, \beta_{j 2}, \ldots, \beta_{j p}$ are the logit coefficients for each comparison.

The odds in the multinomial logistic model can be defined as the ratio of the probability of being in a particular category to the probability of being in the base category, which is the exponential of the logit 
coefficient $\beta$. It is interpreted as the change in the odds for a one-unit change in a predictor variable when holding other predictor variables constant and expressed as follows:

$$
\text { Odds }(Y=j \text { vs. } Y=J)=\frac{p(Y=J)}{p(Y=J)}
$$

where $j$ can be any categories from 1 to $j-1$ categories.

Based on the predictor variables and dependent variable, the following Equation (3) was derived as a multinomial logistic regression model for this study.

$$
\begin{aligned}
\ln \left[\frac{\pi\left(Y=J \mid x_{1}, x_{2}, \ldots \ldots, x_{10}\right)}{\pi\left(Y=J \mid x_{1}, x_{2}, \ldots \ldots . ., x_{10}\right)}\right] \\
=\alpha_{j}+\beta_{j 1} N+\beta_{j 2} E+\beta_{j 3} O+\beta_{j 4} A+\beta_{j 5} C+\beta_{j 6} A g e+\beta_{j 7} G+ \\
\quad \beta_{j 8} Y H I+\beta_{j 9} I E+\beta_{j 10} T o I
\end{aligned}
$$

where $j=0$ indicates low frequency of investment

$j=1$ indicates medium frequency of investment

$j=2$ indicates high frequency of investment

$G=$ Gender (male or female)

$Y H I=$ Yearly household income

$I E=$ Investment experience

ToI = Type of investor (Full time or Part time)

\section{Results and Discussions}

\subsection{Respondents}

This study collected 272 data, but only 231 data was usable for further analysis. Data were excluded because they were non-Malaysian, did not answer the questions accurately and honestly or conflicting responses after the screening process. Table 3 illustrates the characteristics of the respondents.

\subsection{Multinomial Logistic Regression Model}

Table 4 displays the results of parameter estimates and corresponding odds ratios for two binary logistic models comparing each category versus the base category. Model 1 compares $Y=1$ (medium frequency of 
Phaik Nie Chin

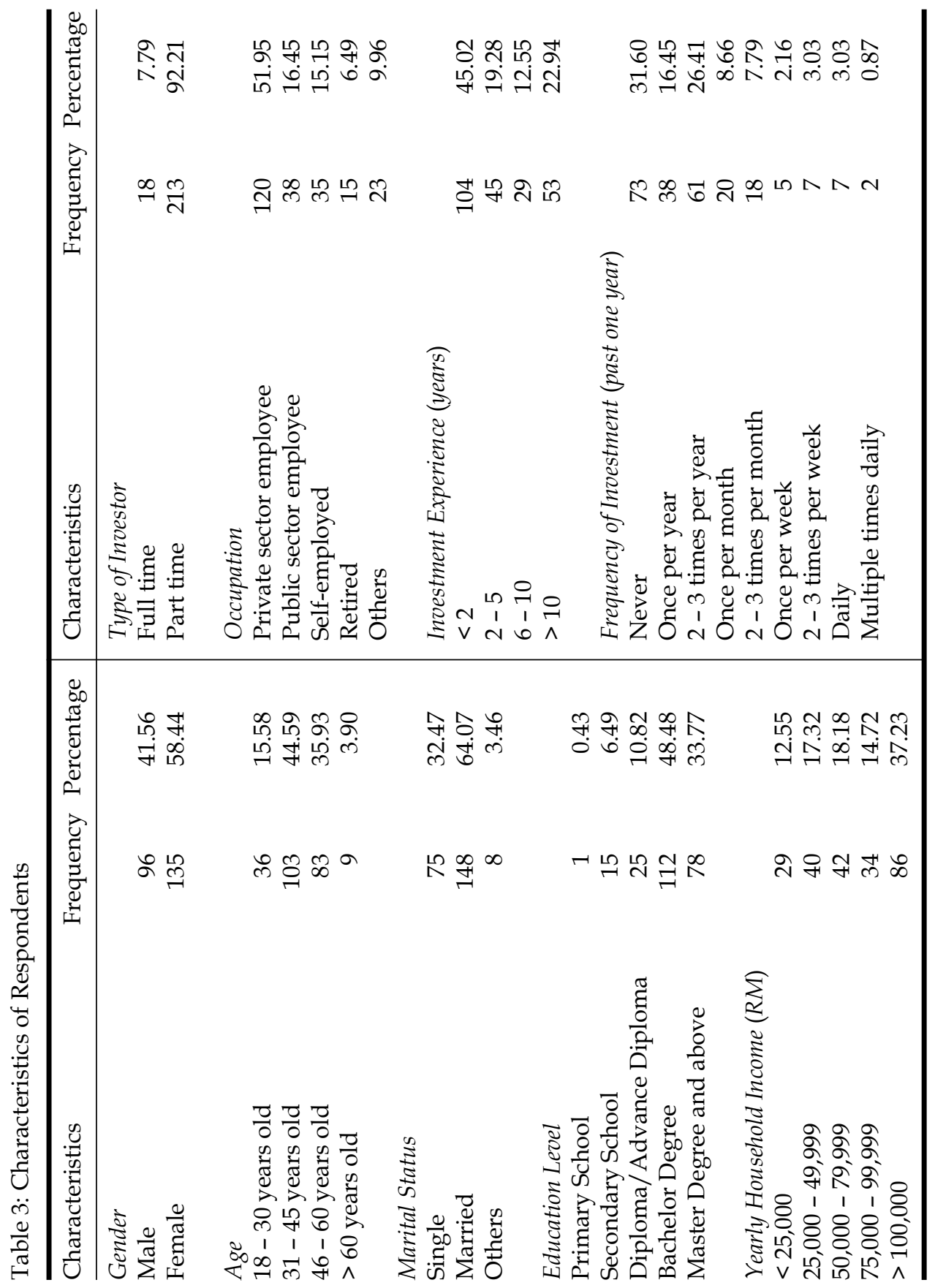


investment) and $Y=0$ (low frequency of investment), whereas model 2 compares $Y=2$ (high frequency of investment) and $Y=0$ (low frequency of investment). To explore a significant level of demographic and socioeconomics factors, and investment behaviours on the frequency of investment, the study had run three multinomial logistic regressions. The first multinomial logistic regression (fitted model A) used five predictor variables (i.e., only the big five personality traits), second multinomial logistic regression (fitted model B) was run with eight predictor variables (i.e., the big five personality traits, gender, age and yearly household income), and the third full model multinomial logistic regression includes the type of investor (i.e., part-time or full time) and year of investment experience. Equations (4) and (5) represent the odds ratio analysis of model 1 and model 2 respectively.

$$
\begin{aligned}
& \text { Odds }(Y=1 \text { vs. } Y=0)=\frac{p(Y=1)}{p(Y=0)}=\frac{p(1)}{p(0)} \\
& \text { Odds }(Y=2 \text { vs. } Y=0)=\frac{p(Y=2)}{p(Y=0)}=\frac{p(2)}{p(0)}
\end{aligned}
$$

\subsubsection{Model Fit}

Model fit refers to a likelihood ratio test comparing the full model with the intercept-only (null model) (Garson, 2014; Liu, 2016; Petrucci, 2009). In the fit stat output, the log-likelihood (LL) for the full model was -161.542 and LL for the intercept-only model was -232.40 . Based on Table 4, the log likelihood ratio chi-square for the full model was $\chi^{2}{ }_{10}=$ $141.72, p<.001$, fitted model B $\chi^{2}{ }_{10}=57.76, p<.001$, and fitted model A $\chi^{2}{ }_{10}=18.19, p<.10$, indicating that the full model provided a better fit than the null model with no predictor variables in predicting the logit of being in any other category of frequency of investment compared with being in the base category.

AIC is the Akaike information criterion and BIC is the Bayesian information criterion. Both are used to measure the model error. The lower the number of AIC and BIC indicates that the model is having a better fit (Garson, 2014; Liu, 2016; Petrucci, 2009). The AIC and BIC for the full model were 367 and 443, fitted model B was 443 and 505, and fitted model A was 471 and 512. The full model is better compared to fitted models B and A based on both AIC and BIC. 
Pseudo R-square is an overall effect size measure for a multinomial logistic regression model (Garson, 2014). Based on Table 4, three pseudo-R-squares (McFadden, Cox and Snell, and Nagelkerke) indicate that the effect size of the model was getting stronger as the study added demographic and socio-economics factors and then investment behaviours in the model. Values from 0.2 to 0.4 for the McFadden were considered "highly satisfactory" (Petrucci, 2009). Results in the fit stat output indicate a significant contribution of demographic and socioeconomic factors and investment behaviours on investors' frequency of investment. Based on the parameter estimates in the output, the two equations for the full model can be expressed as follows:

$$
\begin{aligned}
& \ln \left[\frac{\pi(Y=1)}{\pi(Y=0)}\right]=0.475+0.255 N-0.239 E+0.844 O-1.428 A+0.444 C- \\
& 0.722 \text { Age }-0.363 G+0.325 Y H I+1.773 I E-2.180 T o I \\
& \ln \left[\frac{\pi(Y=2)}{\pi(Y=0)}\right]=-0.506+0.202 N-0.450 E+0.658 O+0.095 A-0.123 C- \\
& .420 \text { Age }-1.111 G+0.491 Y H I+2.488 I E-3.034 T o I
\end{aligned}
$$

\subsubsection{Analysis and Discussion}

This study started the analysis and discussions with the Big Five personality traits based on the full model since it exhibits the best model fit compared with fitted model A and B. For N, OR $(1,0)=1.291, z=0.56$, $p>0.05$, and $\mathrm{OR}(2,0)=1.223, \mathrm{z}=0.31, \mathrm{p}>0.05$, indicating the odd of being in category 1 and 2 versus the base category increased by 1.291 and 1.223 respectively, for a one-unit increase in the $\mathrm{N}$ predictor when holding all other predictors constant. Even though the results are not significant, the results are consistent with past studies (Durand et al., 2008; Shuai et al., 2014; Tauni et al., 2015, 2017), where high $\mathrm{N}$ investors tend to trade more. High $\mathrm{N}$ individuals are more inclined to experience extreme emotions and exhibit irrational behaviour, thus, it might lead them to trade more during the COVID-19 pandemic.

In terms of $E, O R(1,0)=0.787, z=-0.47, p>0.05$ and $\mathrm{OR}(2,0)=0.637$, $\mathrm{z}=-0.68, \mathrm{p}>0.05$, showing no significant relationship between $E$ and the odds of being in any category versus the base category. The results indicate that the odds of being in category 1 and 2 decreased by 0.787 and 0.637 respectively, with one unit increase in the E predictor while 
holding other predictors constant. The findings are not statistically significant but consistent with past studies (Durand et al., 2008, 2013; Shuai et al., 2014; Zhang et al., 2014), where high E investors trade less than low $\mathrm{E}$ investors because they are emotionally stable and more rational. High $\mathrm{E}$ investors exhibit the same trading behaviours even during the COVID-19 pandemic.

Concerning $\mathrm{O}, \mathrm{OR}(1,0)=2.326, \mathrm{z}=1.50, \mathrm{p}>0.05$, and $\mathrm{OR}(2,0)=1.931$, $z=0.93, p>0.05$, which indicates that the odds of being in category 1 and 2 versus the base category increased by 2.326 and 1.931 respectively, with one unit increase in the $\mathrm{O}$ predictor when holding other predictors but not statistically significant. However, these findings are consistent with past studies (Grinblatt \& Keloharju, 2009; Kleine et al., 2016; Pak \& Mahmood, 2015; Tauni et al., 2017), where high O investors engage more in trading. The results show that high $\mathrm{O}$ investors trade more during the COVID-19 pandemic. One of the possible reasons is because high O investors can easily accept new market information and may frequently change investment portfolios with changes in the market situations.

For $\mathrm{A}, \mathrm{OR}(1,0)=0.24, \mathrm{z}=-2.21, \mathrm{p}<0.05$ and $\mathrm{OR}(2,0)=1.1, \mathrm{z}=0.12$, $\mathrm{p}>0.05$, indicating that the odds of being in category 1 and 2 versus the base category decreased by 0.233 and increased by 1.1 respectively, with one unit increase in A predictor when holding other predictors constant. This proves that high A investors trade statistically and significantly less than low A investors when the study compared the medium frequency of trading and low frequency of trading. However, the results show that high A investors trade more when comparing the high frequency of trading and low frequency of trading. The findings are not consistent with past studies (Chang et al., 2020; Durand et al., 2013; Kizys et al., 2021; Shuai et al., 2014; Sun et al., 2021; Tauni et al., 2015, 2017) based on model 1, where high A investors tend to herd and trade more compared with those who are not. The results are consistent for model 2 but not significant. The conflict between the two results could indicate that, during the COVID-19 pandemic, high A investors are still deciding which direction to herd since the market outlook is still uncertain.

The last personality trait is $\mathrm{C}, \mathrm{OR}(1,0)=1.271, \mathrm{z}=0.58, \mathrm{p}>0.05$ and $\mathrm{OR}(2,0)=0.967, \mathrm{z}=-0.06, \mathrm{p}>0.05$, indicating that the odds of being in category 1 versus the base category increased by 1.271, while the odds of being in category 2 versus the base category decreased by 0.967 , with one unit increase in the $\mathrm{C}$ predictor when holding other predictors constant. Results in model 1 are consistent with Durand et al. (2013) and 
Table 4: Results of the Multinomial Logistic Regression Model - 5 Predictors, 8 Predictors and 10 Predictors

\begin{tabular}{|c|c|c|c|c|c|c|}
\hline \multirow[b]{2}{*}{ Variables } & \multicolumn{2}{|c|}{ Fitted model A } & \multicolumn{2}{|c|}{ Fitted model B } & \multicolumn{2}{|c|}{ Full model } \\
\hline & $\mathrm{b}(\mathrm{SE}(\mathrm{b}))$ & OR & $\mathrm{b}(\mathrm{SE}(\mathrm{b}))$ & OR & $\mathrm{b}(\mathrm{SE}(\mathrm{b}))$ & OR \\
\hline \multicolumn{7}{|c|}{ Model $1(Y=1$ vs $Y=0)$} \\
\hline _Ineurotici_1 & $\begin{array}{c}0.0507 \\
(0.356)\end{array}$ & $\begin{array}{c}1.052 \\
(0.374)\end{array}$ & $\begin{array}{c}0.187 \\
(0.392)\end{array}$ & $\begin{array}{l}1.206 \\
(0.472)\end{array}$ & $\begin{array}{c}0.255 \\
(0.455)\end{array}$ & $\begin{array}{c}1.291 \\
(0.588)\end{array}$ \\
\hline _Iextravers_1 & $\begin{array}{c}0.509 \\
(0.382)\end{array}$ & $\begin{array}{c}1.664 \\
(0.636)\end{array}$ & $\begin{array}{c}0.361 \\
(0.407)\end{array}$ & $\begin{array}{c}1.435 \\
(0.585)\end{array}$ & $\begin{array}{l}-0.239 \\
(0.512)\end{array}$ & $\begin{array}{c}0.787 \\
(0.403)\end{array}$ \\
\hline _Iopennesst_1 & $\begin{array}{c}0.924^{*} \\
(0.445)\end{array}$ & $\begin{array}{c}2.519^{*} \\
(1.121)\end{array}$ & $\begin{array}{c}0.974^{*} \\
(0.471)\end{array}$ & $\begin{array}{c}2.647^{*} \\
(1.247)\end{array}$ & $\begin{array}{c}0.844 \\
(0.561)\end{array}$ & $\begin{array}{c}2.326 \\
(1.305)\end{array}$ \\
\hline _Iagreeable_1 & $\begin{array}{l}-1.497^{* *} \\
(0.489)\end{array}$ & $\begin{array}{l}0.224^{* *} \\
(0.109)\end{array}$ & $\begin{array}{l}-1.457^{* *} \\
(0.518)\end{array}$ & $\begin{array}{c}0.233^{* *} \\
(0.121)\end{array}$ & $\begin{array}{l}-1.428^{*} \\
(0.646)\end{array}$ & $\begin{array}{r}0.240^{*} \\
(0.155)\end{array}$ \\
\hline _Iconscient_1 & $\begin{array}{c}0.330 \\
(0.387)\end{array}$ & $\begin{array}{c}1.391 \\
(0.538)\end{array}$ & $\begin{array}{c}0.240 \\
(0.414)\end{array}$ & $\begin{array}{c}1.271 \\
(0.526)\end{array}$ & $\begin{array}{c}0.444 \\
(0.500)\end{array}$ & $\begin{array}{c}1.559 \\
(0.780)\end{array}$ \\
\hline age & & & $\begin{array}{l}-0.131 \\
(0.228)\end{array}$ & $\begin{array}{c}0.877 \\
(0.200)\end{array}$ & $\begin{array}{l}-0.722^{*} \\
(0.301)\end{array}$ & $\begin{array}{r}0.486^{*} \\
(0.146)\end{array}$ \\
\hline _Igender_1 & & & $\begin{array}{l}-1.067^{* *} \\
(0.372)\end{array}$ & $\begin{array}{l}0.344^{* *} \\
(0.128)\end{array}$ & $\begin{array}{l}-0.363 \\
(0.449)\end{array}$ & $\begin{array}{c}0.696 \\
(0.312)\end{array}$ \\
\hline $\begin{array}{l}\text { yearlyhouse } \\
\text { holdincome }\end{array}$ & & & $\begin{array}{l}0.382^{* *} \\
(0.121)\end{array}$ & $\begin{array}{c}1.466^{* *} \\
(0.177)\end{array}$ & $\begin{array}{r}0.325^{*} \\
(0.153)\end{array}$ & $\begin{array}{r}1.385^{*} \\
(0.212)\end{array}$ \\
\hline $\begin{array}{l}\text { investment } \\
\text { experience }\end{array}$ & & & & & $\begin{array}{l}1.773^{* * *} \\
(0.341)\end{array}$ & $\begin{array}{l}5.887^{* * *} \\
(2.008)\end{array}$ \\
\hline _Itypeofinv_2 & & & & & $\begin{array}{l}-2.180 \\
(1.333)\end{array}$ & $\begin{array}{c}0.113 \\
(0.151)\end{array}$ \\
\hline _cons & $\begin{array}{c}0.301 \\
(0.233)\end{array}$ & $\begin{array}{c}1.351 \\
(0.315)\end{array}$ & $\begin{array}{l}0.0922 \\
(0.685\end{array}$ & $\begin{array}{c}1.097 \\
(0.751)\end{array}$ & $\begin{array}{c}0.475 \\
(1.585)\end{array}$ & $\begin{array}{c}1.607 \\
(2.547)\end{array}$ \\
\hline \multicolumn{7}{|c|}{ Model $2(Y=2$ vs $Y=0)$} \\
\hline _Ineurotici_1 & $\begin{array}{l}-0.0806 \\
(0.478)\end{array}$ & $\begin{array}{c}0.923 \\
(0.441)\end{array}$ & $\begin{array}{c}0.0678 \\
(0.543)\end{array}$ & $\begin{array}{c}1.070 \\
(0.581)\end{array}$ & $\begin{array}{c}0.202 \\
(0.641)\end{array}$ & $\begin{array}{c}1.223 \\
(0.784)\end{array}$ \\
\hline _Iextravers_1 & $\begin{array}{c}0.770 \\
(0.469)\end{array}$ & $\begin{array}{c}2.159 \\
(1.013)\end{array}$ & $\begin{array}{c}0.422 \\
(0.526)\end{array}$ & $\begin{array}{c}1.524 \\
(0.802)\end{array}$ & $\begin{array}{l}-0.450 \\
(0.660)\end{array}$ & $\begin{array}{c}0.637 \\
(0.421)\end{array}$ \\
\hline _Iopennesst_1 & $\begin{array}{c}0.608 \\
(0.544)\end{array}$ & $\begin{array}{c}1.837 \\
(0.999)\end{array}$ & $\begin{array}{c}0.692 \\
(0.594)\end{array}$ & $\begin{array}{c}1.998 \\
(1.187)\end{array}$ & $\begin{array}{c}0.658 \\
(0.706)\end{array}$ & $\begin{array}{c}1.931 \\
(1.363)\end{array}$ \\
\hline _Iagreeable_1 & $\begin{array}{l}-0.404 \\
(0.543)\end{array}$ & $\begin{array}{c}0.668 \\
(0.363)\end{array}$ & $\begin{array}{l}-0.204 \\
(0.609)\end{array}$ & $\begin{array}{c}0.815 \\
(0.496)\end{array}$ & $\begin{array}{c}0.0949 \\
(0.823)\end{array}$ & $\begin{array}{c}1.100 \\
(0.905)\end{array}$ \\
\hline
\end{tabular}


Table 4: Continued

\begin{tabular}{|c|c|c|c|c|c|c|}
\hline \multirow[b]{2}{*}{ Variables } & \multicolumn{2}{|c|}{ Fitted model A } & \multicolumn{2}{|c|}{ Fitted model B } & \multicolumn{2}{|c|}{ Full model } \\
\hline & $\mathrm{b}(\mathrm{SE}(\mathrm{b}))$ & OR & $\mathrm{b}(\mathrm{SE}(\mathrm{b}))$ & OR & $\mathrm{b}(\mathrm{SE}(\mathrm{b}))$ & OR \\
\hline _Iconscient_1 & $\begin{array}{c}0.101 \\
(0.498)\end{array}$ & $\begin{array}{l}1.106 \\
(0.550)\end{array}$ & $\begin{array}{l}-0.0336 \\
(0.555)\end{array}$ & $\begin{array}{c}0.967 \\
(0.536)\end{array}$ & $\begin{array}{l}-0.123 \\
(0.691)\end{array}$ & $\begin{array}{c}0.884 \\
(0.611)\end{array}$ \\
\hline age & & & $\begin{array}{l}-0.240 \\
(0.321)\end{array}$ & $\begin{array}{c}0.786 \\
(0.252)\end{array}$ & $\begin{array}{l}-1.420^{* *} \\
(0.457)\end{array}$ & $\begin{array}{l}0.242^{* *} \\
(0.110)\end{array}$ \\
\hline _Igender_1 & & & $\begin{array}{l}-2.093^{* * *} \\
(0.481)\end{array}$ & $\begin{array}{c}0.123^{* * *} \\
(0.0592)\end{array}$ & $\begin{array}{l}-1.111 \\
(0.584)\end{array}$ & $\begin{array}{c}0.329 \\
(0.192)\end{array}$ \\
\hline $\begin{array}{l}\text { yearlyhouse } \\
\text { holdincome }\end{array}$ & & & $\begin{array}{l}0.526^{* *} \\
(0.173)\end{array}$ & $\begin{array}{l}1.693^{* *} \\
(0.293)\end{array}$ & $\begin{array}{l}0.491^{*} \\
(0.212)\end{array}$ & $\begin{array}{c}1.634^{*} \\
(0.346)\end{array}$ \\
\hline $\begin{array}{l}\text { investment } \\
\text { experience }\end{array}$ & & & & & $\begin{array}{l}2.488^{* * *} \\
(0.409)\end{array}$ & $\begin{array}{l}12.04^{* * *} \\
(4.929)\end{array}$ \\
\hline _Itypeofinv_2 & & & & & $\begin{array}{l}-3.034^{*} \\
(1.408)\end{array}$ & $\begin{array}{c}0.0481^{*} \\
(0.0678)\end{array}$ \\
\hline _cons & $\begin{array}{l}-0.868^{* *} \\
(0.313)\end{array}$ & $\begin{array}{l}0.420^{* *} \\
(0.131)\end{array}$ & $\begin{array}{l}-0.892 \\
(0.919)\end{array}$ & $\begin{array}{c}0.410 \\
(0.376)\end{array}$ & $\begin{array}{l}-0.506 \\
(1.800)\end{array}$ & $\begin{array}{c}0.603 \\
(1.085)\end{array}$ \\
\hline $\mathrm{N}$ & \multicolumn{2}{|c|}{231} & \multicolumn{2}{|c|}{231} & \multicolumn{2}{|c|}{231} \\
\hline LR (McFadden's) & \multicolumn{2}{|c|}{0.039} & \multicolumn{2}{|c|}{0.142} & \multicolumn{2}{|c|}{0.305} \\
\hline $\begin{array}{l}\text { ML (Cox and } \\
\text { Snell's) } R^{2}\end{array}$ & \multicolumn{2}{|c|}{0.076} & \multicolumn{2}{|c|}{0.221} & \multicolumn{2}{|c|}{0.459} \\
\hline Nagelkerke $\mathrm{R}^{2}$ & \multicolumn{2}{|c|}{0.087} & \multicolumn{2}{|c|}{0.255} & \multicolumn{2}{|c|}{0.529} \\
\hline Log likelihood & \multicolumn{2}{|c|}{-223.3} & \multicolumn{2}{|c|}{-203.5} & \multicolumn{2}{|c|}{-161.5} \\
\hline LR $\chi^{2}{ }_{10}$ & \multicolumn{2}{|c|}{18.19} & \multicolumn{2}{|c|}{57.76} & \multicolumn{2}{|c|}{141.72} \\
\hline Prob $>\chi^{2}$ & \multicolumn{2}{|c|}{$0.052^{*}$} & \multicolumn{2}{|c|}{$<.001^{* * *}$} & \multicolumn{2}{|c|}{$<.001^{* * *}$} \\
\hline AIC & \multicolumn{2}{|c|}{471} & \multicolumn{2}{|c|}{443} & \multicolumn{2}{|c|}{367} \\
\hline BIC & \multicolumn{2}{|c|}{512} & \multicolumn{2}{|c|}{505} & \multicolumn{2}{|c|}{443} \\
\hline
\end{tabular}

Note: Standard errors in parentheses, ${ }^{*} p<0.05,{ }^{* *} p<0.01,{ }^{* * *} p<0.001$, Coding used in STATA analysis: Personality traits $(\mathrm{N}, \mathrm{E}, \mathrm{O}, \mathrm{A}, \mathrm{C})$ : low $(\mathrm{T}$ score $=<44)=$ code 0 , high $($ T score $>44)=$ code 1 , Gender: Male $=$ code 0 , Female $=$ code 1 , Age: $18-30$ years old $=$ code $1,31-45$ years old $=$ code $2,46-60$ years old $=$ code $3,>60$ years old = code 4, Yearly household income: $<25,000=$ code 1, 25,000 - 49,999 = code 2, 50,000 - 74,999 = code 3, 75,000 - 99,999 = code 4, >100,000 = code 5, Type of investor: Full time $=$ code 1, Part time $=$ code 2 , Investment experience (year): $<2$ $=$ code $1 ; 2-5=$ code $2,6-10=$ code $3 ;>10=$ code 4 , Frequency of investment: never $=$ code 0 , Once per year, 2-3 times per year, Once per month $=$ code 1, $2-3$ times per month, Once per week, 2 - 3 times per week, Daily, multiple times daily $=$ code 2 . 
Tauni et al. (2015), while results in model 2 are consistent with other past studies (Camgoz et al., 2011; Pak \& Mahmood, 2015; Shuai et al., 2014). The findings might imply that high $C$ investors prefer a medium frequency of investment since both models give us contradicting results. This could be because high $\mathrm{C}$ investors are careful, analytical, self-disciplined, and having clear investment goals. Most importantly, they can control their desires to buy stocks with rising prices and sell stocks with falling prices (Camgoz et al., 2011). This leads them to trade moderately even during the COVID-19 pandemic.

In terms of demographic and socio-economic factors based on the full model, $\mathrm{OR}(1,0)=0.486, \mathrm{z}=-2.40, \mathrm{p}<0.05$ and $\mathrm{OR}(2,0)=0.242, \mathrm{z}=$ $-3.11, \mathrm{p}<0.01$, illustrating that the odds of age being in category 1 and category 2 versus the base category significantly decreased by 0.486 and 0.242 , respectively, for a unit increase in the age predictor when holding other predictors constant. These results imply that older investors trade less than younger investors during the COVID-19 pandemic. The results are consistent with Mak and Ip (2017) that age is positively related to trading behaviours. As of gender, $\mathrm{OR}(1,0)=0.696, \mathrm{z}=-0.18, \mathrm{p}>0.05$, and $\mathrm{OR}(2,0)=0.329, \mathrm{z}=-1.90, \mathrm{p}>0.05$, indicating the odds of being in category 1 and category 2 versus the base category for females are 0.696 times and 0.329 times as small as the odds for males respectively but not significant. However, the results are consistent with past research (Barber \& Odean, 2001a; Lewellen et al., 1977; Tauni et al., 2018), where men trade more than women. For yearly household income, $\operatorname{OR}(1,0)=$ $1.385 \mathrm{z}=2.12, \mathrm{p}<0.05$, and $\mathrm{OR}(2,0)=1.634, \mathrm{z}=2.32, \mathrm{p}<0.05$, indicating that the odds of being in category 1 and category 2 versus the base category significantly increased by 1.385 and 1.634, respectively, for a unit increase in the income level predictor when holding other predictors constant. These findings confirm that trading frequency for investors increase when their level of income increase, which is consistent with past studies (Barber \& Odean, 2001b; Chawla, 2014; Mak \& Ip, 2017). The results in demographic and socio-economic factors indicate that these factors do not affect investors' trading frequency differently during the COVID-19 pandemic compared with a normal situation. Based on past research without a global health crisis, younger investors and men have been proven to trade more than older investors and women and those with higher income tended to trade more because they have more extra money for investment. Older investors and women tend to be more risk-averse than younger investors and women. Those 
with higher income tend to trade more because they have more extra money for investment.

In terms of investment behaviours based on the full model, results show a significant relationship between year of investment experience and the odds of being in category 1 and 2 versus the base category. $\mathrm{OR}(1,0)=5.889, \mathrm{z}=5.20, \mathrm{p}<.001$, and $\mathrm{OR}(2,0)=12.04, \mathrm{z}=6.08$, $\mathrm{p}<.001$, indicate that the odds of being in category 1 and 2 significantly increased by 5.889 and 12.04 respectively, with one unit increase in the year of investment experience predictor while holding other predictors constant. These findings are consistent with past findings (Kaustia \& Knüpfer, 2008; Mak \& Ip, 2017; Seru et al., 2010), whereby investors tend to increase their trading frequency when they gain more experiences as they learn through the trading process. The study proves that investment experience is the most vital determinant of trading frequency among all other predictors during the COVID-19 pandemic. For the type of investor, the two binary comparisons demonstrate that two binary comparisons do not show a significant relationship in model 1, but statistically significant in model 2 . OR $(1,0)=0.113, z=-1.64, p>0.05$, and $\operatorname{OR}(2,0)=0.048, \mathrm{z}=-2.15, \mathrm{p}<0.05$, indicate the odds of being in category 1 and 2 versus the base category for part-time investors is 0.113 times and 0.048 times as small as the odds for the full time investors. The results support the notion that full-time investors trade more than part-time investors even in the COVID-19 pandemic especially when the study compares the high frequency of investment with low frequency of investment, which the findings are still limited in current literature.

Based on the above, the study summarises that results in personality traits are consistent with the hypothesis development if the study compares the high frequency of investment and low frequency of investment. During the COVID-19 pandemic, high N, O and A investors tend to trade more because these individuals are emotionally unstable, easily accept new information and change their trading decisions based on the latest market situation and herding behaviours. When the financial market in Malaysia increases due to glove counters, these groups of retail investors tend to herd and increase their trading frequency. High E and C investors are less affected by the COVID-19 pandemic because these individuals are emotionally stable, rational, and very careful in their decision-making. The study also found that demographic, socio-economic factors and investment behaviours continue to play significant roles in the COVID-19 pandemic. These results echo the current findings in the extant literature. 


\section{Conclusion}

The findings conclude that personality traits, demographic, socioeconomic factors, and investment behaviours are playing a role in affecting investors' trading frequency especially age, yearly household income level, years of investment experience and type of investor. Some results are not significant and could be limited by the number of sample size used in this study. This is because multinomial logistic regression prefers a larger sample size (Petrucci, 2009). Therefore, future research can recruit more retail investors to confirm the significance level of those variables. Besides, future research can be conducted after the COVID-19 pandemic to explore whether there is any significant difference in these variables between, during and after the global health crisis. Moreover, future research can include the variable of financial risk tolerance to study the relationship between personality traits and risk tolerance to understand the underlying effect of trading frequency.

In terms of the implication of the study, this study contributes for the first time to current investor behaviour literature in Malaysia, which is still very limited. The study indicates that personality traits, demographic, socio-economic factors, and investment behaviours do affect the trading frequency of Malaysian investors. The results show that among the five Big Five personality traits, high $\mathrm{O}$ and $\mathrm{A}$ investors have a more significant influence on Malaysian investors' trading frequency, which could be different from other countries. Second, personality traits will change over time, and thus, the study is contributing to the current literature by exploring the potential psychological and sociological factors that may affect investors' trading frequency during a global health crisis.

Studies have found that knowledge of behavioural finance enables investors to become aware of how potential biases can affect their investment decisions, and thus, avoiding mental mistakes and errors (Ricciardi \& Simon, 2000). This can eventually promote market efficiency and improve forecasting performance (Daniel et al., 2002). These findings provide insights to financial institutions and individual investors on the importance of personality traits and the type of personality traits that would drive excess trading during the COVID-19 pandemic. High $\mathrm{O}$ and A individuals tend to be more willing to accept novel ideas and new market information, this leads them to change their trading strategies or trading plans more frequently than others. High A investors are also said to be less independent and tend to herd (Shuai et al., 2014). These findings are consistent with the 
herd behaviours exhibited by investors in other countries during the COVID-19 pandemic. If investors recognise their personality traits and the impact of demographic, income level, investment experience and type of investor on their trading decision, it can help them to understand the root cause of their success and failure in trading. It can provide important contributions to avoid serious mistakes in investment analysis and trading profitable investment strategies (Daniel et al., 2002; Fromlet, 2001; Shefrin, 2000). For financial institutions, this information can provide guidelines to top management in identifying the strengths and weaknesses of their employee based on his or her personality traits. It can help managers to plan appropriate training for their employees based on the traits exhibited by the team and thus, lead to better overall performance. Based on the findings, it provides important information to financial institutions that it is important to have a mixture of employee demographic and investment behaviours in a team since employees who are younger, males, and having more years of investment experience tend to trade more frequently. Studies have shown that excessive trading leads to poorer performance (Barber \& Odean, 2000). Besides, it might be good for the manager to group the team based on different personality traits of the employee to improve the team performance. It might be interesting to identify the contribution of this in behavioural finance in future studies.

\section{References}

Akhtar, F., Thyagaraj, K.S., \& Das, N. (2018). Perceived investment performance of individual investors is related to the big-five and the general factor of personality (GPF). Global Business Review, 19(2), 342-356. https://doi. org/10.1177/0972150917713527

Anh, D.L.T., \& Gan, C. (2020). The impact of the COVID-19 lockdown on stock market performance: Evidence from Vietnam. Journal of Economic Studies, 48(4), 836-851. https:// doi.org/10.1108/JES-06-2020-0312

Aziz, A., \& Yi, L.Y. (2020, July 7). RM57b poured into these seven glove stocks since March. The Edge. https://www.theedgemarkets.com/article/ rm5766b-poured-these-seven-glove-stocks-march

Baker, H.K., Kumar, S., \& Goyal, N. (2019). Personality traits and investor sentiment. Review of Behavioral Finance. Advance online publication. https:// doi.org/10.1108/RBF-08-2017-0077

Barber, B.M., \& Odean, T. (2000). Trading is hazardous to your wealth: The common stock investment performance of individual investors. Journal of Finance, 55(2), 773-806. https://doi.org/10.1111/0022-1082.00226 
Barber, B.M., \& Odean, T. (2001a). Boys will be boys: Gender, overconfidence, and common stock investment. Quarterly Journal of Economics, 116(1), 261292. https://doi.org/10.1162/003355301556400

Barber, B.M., \& Odean, T. (2001b). The Internet and the investor. Journal of Economic Perspectives, 15(1), 41-54. https://doi.org/10.1257/jep.15.1.41

Barber, B.M., Odean, T., \& Zhu, N. (2009). Do retail trades move markets? Review of Financial Studies, 22(1), 151-186. https://doi.org/10.1093/rfs/hhn035

Barberis, N., \& Huang, M. (2001). Mental accounting, loss aversion, and individual stock returns. Journal of Finance, 56(4), 1247-1292. https://doi. org/10.1111/0022-1082.00367

Beracha, E., Fedenia, M., \& Skiba, H. (2014). Culture's impact on institutional investors' trading frequency. International Review of Financial Analysis, 31, 34-47. https:// doi.org/10.1016/j.irfa.2013.10.002

Borgatta, E.F. (1964). The structure of personality characteristics. Behavioral Science, 9(1), 8-17. https:// doi.org/10.1002/bs.3830090103

Borghans, L., Duckworth, A.L., Heckman, J.J., \& ter Weel, B. (2008). The economics and psychology of personality traits. Journal of Human Resources, 43(4), 972-1059. https://doi.org/10.3368/jhr.43.4.972

Brown, S., \& Taylor, K. (2014). Household finances and the 'Big Five' personality traits. Journal of Economic Psychology, 45, 197-212. https://doi.org/ 10.1016/j.joep.2014.10.006

Camgoz, S.M., Karan, M.B., \& Ergeneli, A. (2011). Relationship between the Big-Five personality and the financial performance of fund managers. In M. Afzalur Rahim (Ed.), Diversity, Conflict, and Leadership: Current Topics in Management (pp. 137-152). Routledge. https://doi. org/10.4324/9780203793084-7

Chang, C.-L., McAleer, M., \& Wang, Y.-A. (2020). Herding behaviour in energy stock markets during the Global Financial Crisis, SARS, and ongoing COVID-19. Renewable and Sustainable Energy Reviews, 134, Article 110349. https:// doi.org/10.1016/j.rser.2020.110349

Chawla, D. (2014). An empirical analysis of factors influencing investment in mutual funds in India. Global Business Review, 15(3), 493-503. https://doi. org $/ 10.1177 / 0972150914535136$

Chen, G., Kim, K.A., Nofsinger, J.R., \& Rui, O.M. (2007). Trading performance, disposition effect, overconfidence, representativeness bias, and experience of emerging market investors. Journal of Behavioral Decision Making, 20(4), 425-451. https://doi.org/10.1002/bdm.561

Chin, P.N., Ch'ng, K.S., \& Isa, S.M. (2018). The effect of self-serving bias on trading decisions and its solution mechanisms: An experimental study. Global Business and Management Research: An International Journal, 10(1), 6781.

Choe, H., \& Eom, Y. (2009). The disposition effect and investment performance in the futures market. Journal of Futures Markets, 29(6), 496-522. https:/ / doi. org/10.1002/fut.20398 
Cingl, L. (2013). Does herd behaviour arise easier under time pressure? Experimental approach. Prague Economic Papers, 22(4), 558-582. https:// doi.org/10.18267/j.pep.468

Conlin, A., Kyröläinen, P., Kaakinen, M., Järvelin, M.-R., Perttunen, J., \& Svento, R. (2015). Personality traits and stock market participation. Journal of Empirical Finance, 33, 34-50. https:// doi.org/10.1016/j.jempfin.2015.06.001

Costa, P.T., \& McCrae, R.R. (1984). Personality as a life-long determinant of well-being. In C. Malatesca \& C. Izard (Eds.), Affective processes in adult development and aging (pp. 141-157). Sage.

Costa, P.T., \& McCrae, R.R. (2004). Set like plaster? Evidence for the stability of adult personality. In T.F. Heatherton \& J.L. Weinberger (Eds.), Can personality change? (pp. 21-40). American Psychological Association. https:// doi.org/10.1037/10143-002

Costa, P.T., \& McCrae, R.R. (2010). NEO Inventories for the NEO Personality Inventory-3 (NEO-PI-3), NEO Five-Factor Inventory-3 (NEO-FFI-3), NEO Personality Inventory-Revised (NEO PI-R): Professional Manual. Pyschological Assessment Resources.

Daniel, K., Hirshleifer, D., \& Teoh, S.H. (2002). Investor psychology in capital markets: Evidence and policy implications. Journal of Monetary Economics, 49(1), 139-209. https://doi.org/10.1016/S0304-3932(01)00091-5

Digman, J.M., \& Takemoto-Chogk, N.E. (1981). Factors in the natural language of personality: Re-analysis, comparison, and interpretation of six major studies. Multivariate Behavioral Research, 16(2), 149-170. https://doi.org/ $10.1207 / \mathrm{s} 15327906 \mathrm{mbr} 1602 \_2$

Douglas, H.E., Bore, M., \& Munro, D. (2016). Openness and intellect: An analysis of the motivational constructs underlying two aspects of personality. Personality and Individual Differences, 99, 242-253. https://doi.org/10.1016/ j.paid.2016.05.030

Duong, C., Pescetto, G., \& Santamaria, D. (2014). How value-glamour investors use financial information: UK evidence of investors' confirmation bias. European Journal of Finance, 20(6), 524-549. https://doi.org/10.1080/13518 47X.2012.722117

Durand, R., Newby, R., \& Sanghani, J. (2008). An intimate portrait of the individual investor. The Journal of Behavioral Finance, 9(4), 193-208. https:// doi.org/10.1080/15427560802341020

Durand, R., Newby, R., Tant, K., \& Trepongkaruna, S. (2013). Overconfidence, overreaction and personality. Review of Behavioral Finance, 5(2), 104-133. https://doi.org/10.1108/RBF-07-2012-0011

Fama, E.F. (1970). Efficient capital markets: A review of theory and empirical work. The Journal of Finance, 25(2), 383-417. https://doi.org/10.2307/ 2325486

Fama, E.F. (1995). Random walks in stock market prices. Financial Analysts Journal, 51(1), 75-80. https:// doi.org/10.2469/faj.v51.n1.1861 
Faul, F., Erdfelder, E., Lang, A.G., \& Buchner, A. (2007). G*Power 3: A flexible statistical power analysis program for the social, behavioral, and biomedical sciences. Behavior Research Methods, 39(2), 175-191. https://doi. org/10.3758/BF03193146

FBM KLCI. (2020). Bursa Malaysia.

Fernandez-Perez, A., Gilbert, A., Indriawan, I., \& Nguyen, N.H. (2021). COVID- 19 pandemic and stock market response: A culture effect. Journal of Behavioral and Experimental Finance, 29, Article 100454. https://doi. org/10.1016/j.jbef.2020.100454

Fromlet, H. (2001). Behavioral finance - theory and practical application: Systematic analysis of departures from the homo oeconomicus paradigm are essential for realistic financial research and analysis. Business Economics, 36(3), 63-69.

Fung, L., \& Durand, R.B. (2014). Personality traits. In H.K. Baker \& V. Ricciardi (Eds.), Investor behavior: The psychology of financial planning and investing (pp. 99-115). John Wiley \& Sons, Inc. https://doi.org/10.1002/9781118813454. ch6

Garson, G.D. (2014). Logistic regression: Binary and multinomial. Statistical Associates Publishers.

Gervais, S., \& Odean, T. (2001). Learning to be overconfident. Review of Financial Studies, 14(1), 1-27. https://doi.org/10.1093/rfs/14.1.1

Glaser, M., \& Weber, M. (2007). Overconfidence and trading volume. Geneva Risk and Insurance Review, 32(1), 1-36. https://doi.org/10.1007/s10713-0070003-3

Graham, J.R., Harvey, C.R., \& Huang, H. (2009). Investor competence, trading frequency, and home bias. Management Science, 55(7), 1094-1106. https:/ / doi.org/10.1287/mnsc.1090.1009

Grinblatt, M., \& Keloharju, M. (2009). Sensation seeking, overconfidence, and trading activity. The Journal of Finance, 64(2), 549-578. https://doi. org/10.1111/j.1540-6261.2009.01443.x

Heinström, J. (2003). Five personality dimensions and their influence on information behaviour. Information Research, 9(1), 1-24.

Heinström, J. (2010). From fear to flow: Personality and information interaction. Chandos Publishing.

Kahneman, D., \& Tversky, A. (1984). Choices, values, and frames. American Psychologist, 39(4), 341-350. https:// doi.org/10.1037/0003-066X.39.4.341

Kahneman, D., \& Tversky, A. (2013). Prospect theory: An analysis of decision under risk. In L.C. MacLean \& W.T. Ziemba, Handbook of the fundamentals of financial decision making (pp. 99-127). World Scientific. https://doi. org/10.1142/9789814417358_0006

Kaustia, M., \& Knüpfer, S. (2008). Do investors overweight personal experience? Evidence from IPO subscriptions. Journal of Finance, 63(6), 2679-2702. https://doi.org/10.1111/j.1540-6261.2008.01411.x 
Kizys, R., Tzouvanas, P., \& Donadelli, M. (2021). From COVID-19 herd immunity to investor herding in international stock markets: The role of government and regulatory restrictions. International Review of Financial Analysis, 74, Article 101663. https:/ / doi.org/10.1016/j.irfa.2021.101663

Kleine, J., Wagner, N., \& Weller, T. (2016). Openness endangers your wealth: Noise trading and the big five. Finance Research Letters, 16, 239-247. https://doi.org/10.1016/j.frl.2015.12.002

Kourtidis, D., Chatzoglou, P., \& Sevic, Z. (2017). The role of personality traits in investors trading behaviour: Empirical evidence from Greek. International Journal of Social Economics, 44(11), 1402-1420. https:/ / doi.org/10.1108/IJSE07-2014-0151

Lewellen, W.G., Lease, R.C., \& Schlarbaum, G.G. (1977). Patterns of investment strategy and behavior among individual investors. The Journal of Business, 50(3), 296-333. https://doi.org/10.1086/295947

Liu, X. (2016). Applied ordinal logistic regression using stata: From single-level to multilevel modeling. Sage Publications.

Lo, A.W. (1999). The three p's of total risk management. Financial Analysts Journal, 55(1), 13-26. https:// doi.org/10.2469/faj.v55.n1.2238

Lo, A.W. (2004). The adaptive markets hypothesis. Journal of Portfolio Management, 30(5) 15-29. https://doi.org/10.3905/jpm.2004.442611

Lo, A.W. (2005). Reconciling efficient markets with behavioral finance: The adaptive markets hypothesis. Journal of Investment Consulting, 7(2), 21-44.

Mak, M.K.Y., \& Ip, W.H. (2017). An exploratory study of investment behaviour of investors. International Journal of Engineering Business Management, 9, 1-12. https://doi.org/10.1177/1847979017711520

Mayfield, C., Perdue, G., \& Wooten, K. (2008). Investment management and personality type. Financial Services Review, 17(3), 219-236.

McCrae, R.R. (2012). The five-factor model of personality traits: Consensus and controversy. In P.J. Corr \& G. Matthews (Eds.), The Cambridge handbook of personality psychology (pp. 148-161). Cambridge University Press. https:// doi.org/10.1017/cbo9780511596544.012

McCrae, R.R., \& Costa, P.T. Jr. (1997). Personality trait structure as a human universal. American Psychologist, 52(5), 509-516. https://doi.org/10.1037/ 0003-066X.52.5.509

McCrae, R.R., Costa, P.T. Jr., \& Busch, C.M. (1986). Evaluating comprehensiveness in personality systems: The California Q-Set and the five-factor model. Journal of Personality, 54(2), 430-446. https://doi.org/10.1111/ j.1467-6494.1986.tb00403.x

Moosa, I.A., \& Ramiah, V. (2017). Overconfidence and self-serving bias. In The financial consequences of behavioural biases (pp. 45-69). Palgrave Macmillan. https://doi.org/10.1007/978-3-319-69389-7_3

Odean, T. (1998). Volume, volatility, price, and profit when all traders are above average. Journal of Finance, 53(6), 1887-1934. https:// doi.org/10.1111/00221082.00078 
Pak, O., \& Mahmood, M. (2015). Impact of personality on risk tolerance and investment decisions: A study on potential investors of Kazakhstan. International Journal of Commerce and Management, 25(4), 370-384. https:// doi.org/10.1108/IJCoMA-01-2013-0002

Park, J.H., Konana, P., Gu, B., Kumar, A., \& Raghunathan, R. (2013). Information valuation and confirmation bias in virtual communities: Evidence from stock message boards. Information Systems Research, 24(4), 1050-1067. https:// doi.org/10.1287/isre.2013.0492

Petrucci, C.J. (2009). A primer for social worker researchers on how to conduct a multinomial logistic regression. Journal of Social Service Research, 35(2), 193205. https://doi.org/10.1080/01488370802678983

Ricciardi, V., \& Simon, H.K. (2000). What is behavioral finance? Business, Education \& Technology Journal, 2(2), 1-9.

Sadi, R., Asl, H.G., Rostami, M.R., Gholipour, A., \& Gholipour, F. (2011). Behavioral finance: The explanation of investors' personality and perceptual biases effects on financial decisions. International Journal of Economics and Finance, 3(5), 234-241. https:// doi.org/10.5539/ijef.v3n5p234

Seru, A., Shumway, T., \& Stoffman, N. (2010). Learning by trading. Review of Financial Studies, 23(2), 705-739. https://doi.org/10.1093/rfs/hhp060

Shefrin, H. (2000). Beyond greed and fear: Understanding behavioral finance and the psychology of investing. Oxford University Press.

Shiller, R.J., Kon-Ya, F., \& Tsutsui, Y. (1991). Investor behavior in the October 1987 stock market crash: The case of Japan. Journal of the Japanese and International Economies, 5(1), 1-13. https://doi.org/10.1016/S0889-1583(05) 80002-4

Shuai, Z., Zhang, H., Wang, J., Li, J., \& Ouyang, M. (2014). Lateral motion control for four-wheel-independent-drive electric vehicles using optimal torque allocation and dynamic message priority scheduling. Control Engineering Practice, 24(1), 55-66. https://doi.org/10.1016/j.conengprac.2013.11.012

Slovic, P. (1972). Information processing, situation specificity, and the generality of risk-taking behavior. Journal of Personality and Social Psychology, 22(1), 128-134. https://doi.org/10.1037/h0032370

Smales, L.A. (2021). Investor attention and global market returns during the COVID-19 crisis. International Review of Financial Analysis, 73, Article 101616. https://doi.org/10.1016/j.irfa.2020.101616

Specht, J., Egloff, B., \& Schmukle, S.C. (2011). Stability and change of personality across the life course: The impact of age and major life events on meanlevel and rank-order stability of the Big Five. Journal of Personality and Social Psychology, 101(4), 862-882. https://doi.org/10.1037/a0024950

Statman, M., Thorley, S., \& Vorkink, K. (2006). Investor overconfidence and trading volume. Review of Financial Studies, 19(4), 1531-1565. https://doi. org $/ 10.1093 / \mathrm{rfs} / \mathrm{hhj} 032$

Sun, Y., Bao, Q., \& Lu, Z. (2021). Coronavirus (Covid-19) outbreak, investor sentiment, and medical portfolio: Evidence from China, Hong Kong, 
Korea, Japan, and US. Pacific-Basin Finance Journal, 65, Article 101463. https://doi.org/10.1016/j.pacfin.2020.101463

Tauni, M.Z., Fang, H.X., \& Iqbal, A. (2017). The role of financial advice and word-of-mouth communication on the association between investor personality and stock trading behavior: Evidence from Chinese stock market. Personality and Individual Differences, 108, 55-65. https://doi. org/10.1016/j.paid.2016.11.048

Tauni, M.Z., Fang, H.X., Rao, Z.R., \& Yousaf, S. (2015). The influence of investor personality traits on information acquisition and trading behavior: Evidence from Chinese futures exchange. Personality and Individual Differences, 87, 248-255. https://doi.org/10.1016/j.paid.2015.08.026

Tauni, M.Z., Majeed, M.A., Mirza, S.S., Yousaf, S., \& Jebran, K. (2018). Moderating influence of advisor personality on the association between financial advice and investor stock trading behavior. International Journal of Bank Marketing, 36(5), 947-968. https://doi.org/10.1108/IJBM-10-2016-0149

Topcu, M., \& Gulal, O.S. (2020). The impact of COVID-19 on emerging stock markets. Finance Research Letters, 36, Article 101691. https://doi.org/ 10.1016/j.frl.2020.101691

Wagner, A.F. (2020). What the stock market tells us about the post-COVID-19 world. Nature Human Behaviour, 4(5), 440-440. https://doi.org/10.1038/ s41562-020-0869-y

Wang, H., Zhang, J., Wang, L., \& Liu, S. (2014). Emotion and investment returns: Situation and personality as moderators in a stock market. Social Behavior and Personality: An International Journal, 42(4), 561-569. https://doi. org/10.2224/sbp.2014.42.4.561

Xu, R., Frey, R.M., Fleisch, E., \& Ilic, A. (2016). Understanding the impact of personality traits on mobile app adoption - Insights from a largescale field study. Computers in Human Behavior, 62, 244-256. https://doi. org/10.1016/j.chb.2016.04.011

Zhang, J., Wang, H., Wang, L., \& Liu, S. (2014). Is there any overtrading in stock markets? The moderating role of Big Five personality traits and gender in a unilateral trend stock market. PLoS ONE, 9(1), Article e87111. https://doi. org/10.1371/journal.pone.0087111

Zhang, Y., \& Zheng, X. (2015). A study of the investment behavior based on behavioral finance. European Journal of Business and Economics, 10(1), 1-5. https://doi.org/10.12955/ejbe.v10i1.557 
